Irving Lutsky vMD, Margaret Hopwood MA RN, Stephen E. Abram MD, James M. Cerletty MD, Raymond G. Hoffman PhD, John P. Kampine MD PhD

\title{
Use of psychoactive substances in three medical specialties: medical specialties: and surgery
}

In order to determine the prevalence of psychoactive substance use in three specialty groupings, 1,624 questionnaires were sent to physicians in medicine, surgery and anaesthesia; all had trained at the same academic institution. $A$ response rate of $57.8 \%$ was achieved. Comparison of prevalence of impairment rates showed no differences between Surgery (14.4\%), Medicine (19.9\%) and Anaesthesia (16.8\%). Substance abuse was clearly associated with a family history of abuse; $32.1 \%$ of the abusers had a family history of such abuse compared with $11.7 \%$ of the non-abusers. Increased stress at various career stages did not appear to increase substance abuse; problem areas during medical life times were similar for each specialty. Substances most frequently used were marijuana (54.7\%), amphetamines (32.9\%); and benzodiazepines (25.1\%). Seventy-three used psychoactive drugs which were non-prescribed. Drug counselling programmes were judged inadequate by most. Use of alcohol and drugs by faculty members was reported by a number of respondents.

Dans le but de déterminer lhabitude des produits psychoactifs chez trois groupes de spécialistes, 1,624 questionnaires ont été

\section{Key words}

ALCOHOL: abuse; ANALEPTICS: amphetamine abuse; ANAESTHETISTS: substance abuse; ATARACTICS: abuse, marijuana; HYPNOTICS: benzodiazepines, abuse; PHYSICIANS: impaired.

From the Departments of Anesthesiology, Medicine and Clinical Epidemiology, Medical College of Wisconsin, Milwaukee, Wisconsin, and the Department of Comparative Medicine, Hebrew University School of Medicine, Jerusalem, Israel.

Address correspondence to: Professor Irving Lutsky, Chairman, Department of Comparative Medicine, Hebrew University School of Medicine, P.O.B. 12272, 91120 Jerusalem, Israel.

Accepted for publication 28th March, 1994. expédiés à des internistes, des chirurgiens et à des anesthésistes. Tous avaient reçu leur formation à la même institution. Le taux de réponse a été de $57,8 \%$. La fréquence ne differe pas entre chirurgiens (14,4\%), internistes (19,9\%) et anesthésistes (16,8\%). Lusage des toxiques est nettement associée à une histoire familiale d'abus des drogues; $32,1 \%$ des utilisateurs avaient une histoire familiale positive comparativement à $11,7 \%$ des non utilisateurs. L'augmentation du stress à des moments variés de la vie profesionnelle ne semble pas influer sur labus des toxiques; les périodes de difficultés professionnelles sont identiques pour les trois disciplines. Les substances les plus utilisées sont la marihuana $(54,7 \%)$, les amphétamines $(32,9 \%)$ et les benzodiazépines $(25,1 \%)$. Soixante-treize des répondants ont fait usage de médicaments psychoactifs non prescrits. La plupart ont jugé les programmes d'aide inadéquats. L'utilisation de l'alcool et des drogues par le personnel médical a été rapportée par une certain nombre de répondants.

The shifting emphases of work-related personal concerns among physicians, e.g., epidemic AIDS, professional liability litigation, and physician oversupply may have currently relegated the problem of substance abuse to a less prominent position. Nevertheless, abuse of alcohol and psychoactive drugs continues as a leading factor in physician impairment. Accumulation of information concerning psychoactive substance use by physicians could afford insights into the efficacy of programmes for prevention and control in addition to providing basic epidemiologic data.

The use of psychoactive substances among medical students, residents, and practicing physicians has been well documented. ${ }^{1-15}$ Furthermore, some medical specialty groups are believed to have a higher risk for the development of chemical dependence. ${ }^{16}$ For example, while only $3 \%$ of practicing physicians in the U.S.A. are anaesthetists, $13 \%$ of a group of drug-dependent physicians in treatment, practiced in that specialty. ${ }^{17}$ Although no generally accepted reasons for such over-representation have been put forth, the ease of workplace access to 
opioids, anaesthetics, and other psychotropic medications has been thought to contribute to this observation. ${ }^{11,18}$

One objective of this study was to ascertain the prevalence of psychoactive substance use in three specialty groupings of physicians trained at the same academic institution. Other goals included perception of preventive programmes, and ascertaining the effect of personal stress on substance abuse.

In a preliminary study ${ }^{19}$ we examined problems of substance use in anaesthetists who had trained at The Medical College of Wisconsin (MCW), Milwaukee, Wisconsin. Substance abuse, primarily alcohol, was a sizable problem (15.9\%) in this group; in most cases dependency had begun before residency. In the present study, we report the experience of $824 \mathrm{MCW}$-trained physician specialists (medicine, surgery, and anaesthesia) with psychoactive substances.

\section{Methods}

\section{Study population}

The study population comprised 824 physician specialists who had completed their specialty training at $\mathrm{MCW}$, and had responded to our survey questionnaire.

For the purpose of comparing substance use by specialty group, the following specialties were characterized: medicine, surgery and anaesthesia.

"Medicine" $(n=403)$ included internal medicine (199), family medicine and general practice (54), paediatrics (43), radiology (41), dermatology (13), neurology (11), allergy (10), nephrology (8), emergency medicine (7), oncology (5), physical medicine and rehabilitation (5), endocrinology (2), infectious diseases (2) and aerospace medicine, geriatrics, occupational medicine ( 1 each).

"Surgery" (239) included general surgery (86), ophthalmology (47), orthopaedics (36), obstetrics and gynaecology (32), ENT (20), urology (13), and proctology and colo-rectal surgery (5).

"Anaesthesia" comprised $183 \mathrm{MCW}$-trained anaesthetists who had completed a similar questionnaire in an earlier survey. ${ }^{19}$

\section{Survey materials and procedures}

A 58-item multiple choice questionnaire, developed for use in the survey, requested socio-demographic information, self-reported past and present patterns of substance use, current professional status, a report of perceived substance use by peers and faculty/supervisors during residency, and an evaluation of substance control and abuse prevention programmes carried out during training. Before distribution, the questionnaire was pre-tested in a group of local physicians; an average of $20 \mathrm{~min}$ was required for completion.
A completed questionnaire, sealed in a blank envelope, and inserted into a second pre-stamped and postmarked envelope, was returned to a rented post office box. Thus, respondents were assured of anonymity. Results from other questionnaire surveys concerning drug use have shown that little response bias occurs when respondents are certain that their anonymity has been safeguarded. ${ }^{20}$

A second set of identical materials was sent to the same population two months after the initial mailing. A revised covering letter requested their participation had they not replied previously.

Questionnaires $(n=1166)$ were sent to practicing physicians in the specialties of medicine and surgery who had completed residency training at MCW; 641 completed questionnaires were received. Previously, a similar questionnaire $(n=260)$ instrument elicited information concerning psychoactive substance use from $183 \mathrm{MCW}$ trained anaesthetists.

\section{Criteria for drug and/or alcohol impairment}

Drug impairment was established on the basis of one or more of these criteria: (a) ability to function professionally compromised by psychoactive drugs, prescribed or not prescribed; (b) two or more "yes" replies to "CAGE"21 questions on drugs; (c) admitted history of inpatient and/or outpatient treatment for drugs; or (d) acknowledgement of drug dependency.

Alcohol impairment was based on: (a) acknowledgement that alcohol had impaired their professional function; (b) two or more "yes" replies to "CAGE" questions on alcohol; (c) inpatient and/or outpatient treatment status for an alcohol problem.

\section{Statistical analysis}

Questionnaire data were analyzed statistically either by chi-square analysis or the $t$ test for proportions. Comparisons among the groups were made using chi-square analyses. The chi-square test for trend in proportions examined the effect of age on impairment. ${ }^{22}$ Multiple linear regression analysis was used to compare rates adjusted for sex, country of origin and decade of birth. ${ }^{23}$ The results from the previous study of anaesthesia residents were compared to the results from the present survey of medicine and surgery residents.

\section{Results}

Completed questionnaires were returned by 403 physicians in medicine, 238 in surgery and 183 anaesthetists. This total of 824 replies represented a combined average response rate of $57.8 \%$.

More than one-third (35.4\%) of physicians responding were born before 1931 with an additional $54.1 \%$ born between 1931 and 1951 . More than $91 \%$ were born in 
the United States, and $90.4 \%$ were Caucasian. Table I provides demographic data describing the sex, race, nationality, and relative age of the respondents. On comparison, it was found that Anaesthetists in this survey differed $(P<0.001)$ from specialists in medicine and surgery in all four categories listed. In addition, the specialty of medicine, as represented, was different from surgery for country of birth and decade of birth.

The domestic status of these respondents at the time of our survey showed that a great majority $(90.8 \%)$ were married or had been previously married (5.0\%). Most of them (56.0\%) had married before the residency period; an additional $17 \%$ married while residents. The effect of substance use on marital status was substantial: the divorce rate among impaired anaesthetists (34.5\%) was greater $(P<0.001)$ than that of their impaired colleagues in medicine (4.3\%) and surgery ( $8.0 \%)$. No other comparisons involving marital status were significantly different.

Impairment in the three specialties is shown in Table II. A comparison of the prevalence of impairment rates shows no significant differences between surgery, anaesthesia and medicine before or after adjustment for demographic differences among the specialties.

On examining the occurrence of impairment as related to age (Table III) we noted a greater prevalence of impairment among younger surgeons and anaesthetists. In medicine, greater prevalence of impairment was found in older physicians, $40 \mathrm{yr}$ and over, than in similarly aged anaesthetists or surgeons. Impairment appeared unrelated to the completion date of residency. Although the test for trend in proportions was significant for both surgery and anaesthesia, there was no clear linear trend in either group.

Substance abuse was clearly associated with a family history of abuse; $32.1 \%$ of the abusers had a family history of such abuse, compared with $11.7 \%$ of the nonabusers. A number of respondents reported alcohol (3.5\%) and drug (3.3\%) problems involving their children.

Recognizing that substance use might be stress-related, we evaluated the relative severity of concern with 14 problem areas before residency (high school, pre-medical studies, medical school), during residency, and in medical practice. The major personal concerns during their medical careers (Table IV) showed a great deal of similarity among the specialties represented. Not surprisingly, both during the pre-residency and residency periods, concern over finances was the greatest problem for all specialty groups. Sexual issues also appeared to be a common worry. Malpractice, while listed among their first four concerns by both practicing internists and surgeons, did not appear among the four major worries of anaesthetists. Neither alcohol nor drug problems ever appeared to be
TABLE I Demographic data of 824 survey respondents (\%)

\begin{tabular}{lccl}
\hline & $\begin{array}{c}\text { Medicine } \\
n=403\end{array}$ & $\begin{array}{c}\text { Surgery } \\
n=238\end{array}$ & $\begin{array}{l}\text { Anaesthesia } \\
n=183\end{array}$ \\
\hline Sex & & & \\
Male & 93.2 & 96.2 & $84.2^{*}$ \\
Female & 6.8 & 3.8 & 15.8 \\
Race & & & \\
Caucasian & 93.5 & 97.0 & $79.2^{*}$ \\
Non-Caucasion & 6.5 & 3.0 & 20.8 \\
Country of birth & & & \\
USA & $92.5 \dagger$ & 97.0 & $73.2^{*}$ \\
Other & 7.5 & 3.0 & 26.8 \\
& & & \\
Decade of birth & & & \\
S1950 & $87.3 \dagger$ & 93.7 & $61.0^{*}$ \\
$>1950$ & 12.7 & 6.3 & 39.0 \\
\hline
\end{tabular}

*Anaesthesia different from Medicine and surgery, $P<0.001$. $\dagger$ Medicine different from surgery, $P<0.01$.

TABLE II Prevalence of psychoactive substance impairment in physicians in three medical specialties: medicine $(n=403)$, surgery $(n=238)$, and anaesthesia $(n=183)$

\begin{tabular}{llll}
\hline & $\begin{array}{l}\text { Medicine } \\
\%\end{array}$ & $\begin{array}{l}\text { Surgery } \\
\%\end{array}$ & $\begin{array}{l}\text { Anaesthesia } \\
\%\end{array}$ \\
\hline Unadjusted percentage & 19.9 & 15.1 & 15.9 \\
Adjusted percentage* $^{*}$ & 19.9 & 14.4 & 16.8 \\
\hline
\end{tabular}

*Adjusted for sex, decade of birth, country of origin by multiple linear regression.

of paramount concern at any one stage, and were never rated higher than seventh place in importance.

The use of alcohol, at least once in their lifetime was reported by $92.5 \%$ of the respondents. Alcohol consumption in the three specialties began at an average age of seventeen. During residency, consumption of alcohol showed a net decrease of $10 \%$. During this same period there were no changes in drug use.

Forty-four respondents reported using psychoactive drugs prescribed by physicians other than themselves, with the first use occurring at almost any age (range: $<20->50 \mathrm{yr}$ ). Thirty-nine of them utilized these psychoactive drugs for the express purpose prescribed; a small number, 5 of 44, used the drugs for other purposes.

When asked whether they had ever used drugs to "get high," $243(29.4 \%)$ answered affirmatively. The drugs most frequently employed were: marijuana (54.7\%), amphetamines (32.9\%), benzodiazepines (25.1\%), barbiturates / hypnotics $(13.1 \%)$, codeine (10.6\%), cocaine (5.8\%), an psychedelics (4.9\%). The reasons given for drug use are shown in Table V.

Seventy-three (8.9\%) respondents acknowledged their 
TABLE III Impairment from substance abuse in specialties as related to decade of birth

\begin{tabular}{|c|c|c|c|c|}
\hline \multirow[b]{2}{*}{ Decade of birth } & \multicolumn{2}{|c|}{ Medicine } & \multirow{2}{*}{$\frac{\text { Surgery }}{\text { No.Impaired (\%) }}$} & \multirow{2}{*}{$\begin{array}{l}\text { Anaesthesia } \\
\text { No. Impaired (\%) }\end{array}$} \\
\hline & No. & Impaired (\%) & & \\
\hline$<1920$ & 48 & 8.3 & 2412.5 & 211.1 \\
\hline $1920-1930$ & 99 & 23.2 & $48 \quad 12.5$ & $18 \quad 11.1$ \\
\hline $1931-1940$ & 96 & 17.7 & $84 \quad 11.9$ & $40 \quad 7.5$ \\
\hline $1941-1950$ & 107 & 24.3 & 6618.2 & $51 \quad 15.7$ \\
\hline $1951-1960$ & 51 & 19.6 & 1531.3 & 7123.6 \\
\hline \multirow[t]{2}{*}{$1961+$} & - & - & 131.3 & 123.6 \\
\hline & \multicolumn{2}{|c|}{$* X^{2}=1.55(\mathrm{NS})$} & $\begin{array}{l}X^{2}=4.79 \\
(P<0.03)\end{array}$ & $\begin{array}{l}X^{2}=5.38 \\
(P<0.02)\end{array}$ \\
\hline
\end{tabular}

$* \mathrm{X}^{2}$ test for trend with 1 d.f.

TABLE IV Areas of major personal concern during a career in medicine

\begin{tabular}{|c|c|c|c|}
\hline \multirow[b]{2}{*}{ Career phase } & \multicolumn{3}{|l|}{ Specialty } \\
\hline & Medicine & Surgery & Anaesthesia \\
\hline Before residency (med school, pre-med) & $\begin{array}{l}\text { Finances } \\
\text { Competence } \\
\text { Death/loss } \\
\text { Sexual issues } \\
\text { Marital problems }\end{array}$ & $\begin{array}{l}\text { Finances } \\
\text { Emotional/psych } \\
\text { Sexual issues } \\
\text { Marital problems }\end{array}$ & $\begin{array}{l}\text { Finances } \\
\text { Marital problems } \\
\text { Emotional problems } \\
\text { Sexual issues }\end{array}$ \\
\hline During residency & $\begin{array}{l}\text { Finances } \\
\text { Marital problems } \\
\text { Competence } \\
\text { Emotional psych. }\end{array}$ & $\begin{array}{l}\text { Finances } \\
\text { Marital problems } \\
\text { Competence } \\
\text { Sexual issues }\end{array}$ & $\begin{array}{l}\text { Finances } \\
\text { Interpersonal problems } \\
\text { Marital problems } \\
\text { Emotional psych. }\end{array}$ \\
\hline Practice of medicine & $\begin{array}{l}\text { Physical problems } \\
\text { Malpractice } \\
\text { Marital problems } \\
\text { Aging }\end{array}$ & $\begin{array}{l}\text { Marital problems } \\
\text { Physical problems } \\
\text { Death/loss } \\
\text { Malpractice }\end{array}$ & $\begin{array}{l}\text { Aging } \\
\text { Sexual issues } \\
\text { Marital problems } \\
\text { Interpersonal }\end{array}$ \\
\hline
\end{tabular}

TABLE V Reasons offered for drug use during various phases of medical career

\begin{tabular}{llcl}
\hline & \multicolumn{2}{l}{ Number replying } & \\
\cline { 2 - 4 } Reasons & $\begin{array}{l}\text { Pre-med; } \\
\text { Med school }\end{array}$ & Residency & $\begin{array}{l}\text { Medical } \\
\text { practice }\end{array}$ \\
\hline Euphoria & 67 & 32 & 43 \\
Analgesia & 6 & 8 & 40 \\
Anxiolysis & 11 & 13 & 21 \\
Boredom & 10 & 5 & 9 \\
To prevent dysphoria on & & 0 & \\
$\quad$ withdrawal & 1 & 29 & 68 \\
Other & 69 & & \\
\hline
\end{tabular}

use of psychoactive drugs not prescribed by a physician, other than themselves. Five admitted they had on occasion impaired their ability to function professionally as a result of utilizing these non-prescribed drugs. At the time of the survey, 13 still continued their use of these substances.

The pattern of psychoactive substance use in $145 \mathrm{im}$ paired specialists is displayed in Table VI. The use by anaesthetists of marijuana and psychedelic drugs differed $(P<0.001)$ from medicine and surgery. Use of potent short-acting opioids (the fentanyl group) was seen only in anaesthetists for whom these were routine workplace drugs.

When asked whether workplace ease of access to psychoactive substances influenced their selection of career or specialty, $99.7 \%$ of non-impaired and $98.5 \%$ of impaired physicians registered an emphatic negative. Four physicians, two non-impaired and two impaired, acknowledged that ease of access to drugs had played a role in their choice of career; in the case of one abuser it had played an important role.

Physicians were asked whether counselling and infor- 
TABLE VI Percent of impaired physicians in three specialty groups related to type of substance used

\begin{tabular}{llll}
\hline Substance & $\begin{array}{l}\text { Anaesthesia } \\
(n=29)\end{array}$ & $\begin{array}{l}\text { Surgery } \\
(n=36)\end{array}$ & $\begin{array}{l}\text { Medicine } \\
(n=80)\end{array}$ \\
\hline Alcohol & $100 \%$ & $100 \%$ & $97.5 \%$ \\
Marijuana* & $55.2^{*}$ & 33.3 & 25 \\
Amphetamine/ritalin & 17.2 & 13.9 & 20 \\
Cocaine & 13.8 & 2.8 & 5 \\
Sedatives & 27.6 & 16.7 & 18.8 \\
Opioids & & & \\
- Codeine & 6.9 & 11.1 & 10.0 \\
- Meperidine & 3.4 & 2.8 & 2.5 \\
- Opium & 3.4 & 2.8 & 0 \\
- Hydrocodone & 3.4 & 5.6 & 3.8 \\
- Oxycodone & 3.4 & 0 & 1.3 \\
- "Other" narcotics & 3.4 & 0 & 0 \\
- Fentanyl; & & & \\
$\quad$ - Sufentanil/alfentanil & 10.3 & 0 & 0 \\
Psychedelics & $16.5^{*}$ & 2.8 & 2.5 \\
\hline
\end{tabular}

$* P<0.01$.

mation on alcohol and drug abuse had represented an important element of their residency training; almost $90 \%$ replied in the negative. Seventy-eight percent of those replying to this question felt that the subject had been barely touched on or had only been slightly in evidence. When asked to evaluate their training hospital's system of drug and substance control, 496 physicians (62.2\%) did not respond. Among those replying, $48 \%$ judged the system as having been "fair to poor."

Several questions addressed the subject of substance use by faculty as well as students. The detrimental use of alcohol by one or more faculty members was witnessed by 219 respondents. In 99 occurrences, the use of alcohol took place while these teachers were professionally engaged, and in 81 instances the observers judged that their teachers' ability to function professionally had been impaired. Most respondents ( $n=94$ ) reported having seen less than five different teachers using alcohol detrimentally, while one observer claimed to have seen more than ten teachers thus involved.

The detrimental use of drugs by one or more teachers was observed by 25 residents; in 17 cases, these faculty members were professionally engaged. In 15 instances drug usage had impaired the teachers' ability to function professionally. As with alcohol usage, most respondents recalled fewer than five different teachers involved.

During training, residents were observed using psychoactive substances by fellow residents. Their use of alcohol while professionally engaged was noted by 58 $(7.0 \%)$ of the respondents, 23 of whom noted these infractions on five or less occasions, with 13 recalling occurrences on six or more occasions. When asked to recall how many different residents were seen using alcohol while professionally engaged, 46 observed more than five, 11 noted from five to ten residents, and three recalled more than ten persons involved.

Thirty-four respondents (4.1\%) observed detrimental use of drugs on a number of occasions by residents professionally engaged. They judged that 28 of these drug users sustained impairment to their ability to function professionally.

Infractions involving alcohol and drug use both by faculty and residents went largely unreported (Table VII). There were no differences in reporting rates between the impaired and unimpaired physicians, even though the impaired were more likely to observe infractions. A drug infraction was more likely to be reported $(P<0.001)$ than an alcohol infraction (two to four times more likely), even though there were fewer drug infractions observed.

\section{Discussion}

Although anaesthesia has been reported to lead all medical specialties in levels of substance abuse, our data do not support this allegation. On the contrary, no differences in the prevalence of impairment by psychoactive substances among three specialty groupings: medicine (19.9\%), anaesthesia $(16.8 \%)$ and surgery $(14.4 \%)$ could be demonstrated.

A partial explanation of these results is that most reports comparing prevalence of substance abuse among medical specialties are based on information furnished by treatment and monitoring programmes for impaired professionals. Since these other studies deal only with physicians whose dependency has already been determined, conclusions based on such evidence should be drawn with caution.

The differences for country of birth, sex, and race may result from several factors. The large number of foreignborn anaesthetists reflects in part the diminished recruitment of American graduates in the mid-1960's to the 1980's. As regards race, there has been a conscious effort to recruit non-Caucasians into the anaesthesia residency programme.

It has generally been believed that the residency period is one of great stress and personal turmoil leading to increased substance use. While this may seem a reasonable theory, our data indicated that the alleged stresses of the residency period were not reflected by any changes in the use of sedatives, stimulants, opioids, alcohol, marijuana or cocaine, regardless of whether or not the respondents were abusers.

Drug use by anaesthetists does involve some differences from the specialties of medicine and surgery, especially in the type and kind of drug. One plausible reason for the anaesthetist's more frequent use of fentanyl is that 


\begin{tabular}{lr} 
TABLE VII & Peer rep \\
\hline & Fac \\
& $\frac{\% \text { c }}{A l a c}$ \\
& 8.99 \\
\hline Impaired & $6.5 \%$ \\
\hline Unimpaired &
\end{tabular}

* $P<0.001$, percent of unimpaired physicians.

it represents his se available in his wo and psychedelics 1 sample; they are $n$

Two consistent substance abuse $\mathbf{b}$ stitution has dev gramme, and (2) successful in prev time and effort gir minimal, since aln drug use preventi training. Most st grammes establist stance abuse prob equate.

These preventiv they are often ins most drug use $w$ : school. The progr because there are ing methods; urir most persons whe under-identificatio against deterrena grammes fail bec: are insufficiently $s$ resents yet anothe in physicians train

In summary, w psychoactive drug of specialists in a of whom had recei ical College of $v$ within this popula the three specialty psychoactive subs over-representatio ment programmes is related to better detection procedures rather than greater use. Examination of the reasons offered for drug use and the types of substances used revealed no differences among the three specialties.

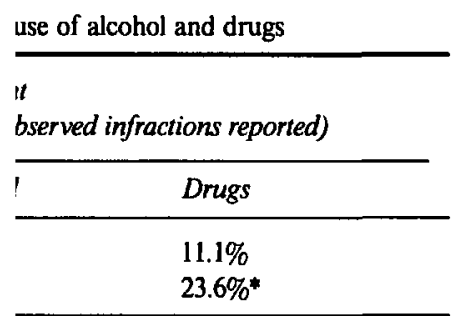

$\mathrm{g}$ infractions, pooling impaired and

Few studies involving substance use by medical students have dealt with substance usage by faculty members. While our survey indicated that respondents observed faculty use of drugs and alcohol, it was not possible from the questionnaire to determine if such use was observed during patient care or during other professional activities. Furthermore, it was not possible to determine with certainty if these were multiple observations of a few individuals or a much larger number of faculty, since all of the observations occurred in the same institution and its various training programmes.

\section{References}

1 Clark DC. Alcohol and drug use and mood disorders among medical students: implications for physician impairment. QRB Qual Rev Bull 1985; 14: 50-4.

2 McAuliffe WE, Rohman M, Fishman P, et al. Psychoactive drug use by young and future physicians. J Health Soc Behav 1984; 25: 34-54.

3 Baldwin DC Jr, Conard S, Hughes P, Achenbach KE, Sheehan $D V$. Substance use and abuse among senior medical students in 23 medical schools. Proceedings of the Annual Conference on Research in Medical Education 1988; 27: 262-7.

4 Kory WP, Crandall LA. Nonmedical drug use patterns among medical students. Int J Addict 1984; 19: 871-84.

5 Maddux JF, Hoppe SK, Costello RM. Psychoactive substance use among medical students. Am J Psychiatry 1986; 1432: 187-91.

6 Ward CF, Ward GC, Saidman $L J$. Drug abuse in anesthesia training programs. JAMA 1983; 250: 922-5.

7 Urbach JR, Levenson JL, Harbison JW. Perceptions of housestaff stress and dysfunction within the academic; medical center. Psychiatr Q 1989; 60: 283-96.

8 Conard SE, Hughes P, Baldwin D, Achenbach $K$, Sheehan $D$. Substance use and the resident physician: a national study. Proceedings of the Annual Conference on Research in Medical Education 1988; 27: 256-61.

9 Maddux JF, Timmerman IM, Costello RM. Use of psychoactive substances by residents. Journal of Medical Education 1987; 62: 852-4. 
10 Sethi $B B$, Manchanda $R$. Drug abuse among resident doctors. Acta Psychiatr Scand 1980; 62: 447-55.

11 Gallegos $K V$, Browne $C H$, Veit $F W$, Talbott GD. Addiction in anesthesiologists: drug access and patterns of substance abuse. QRB Qual Rev Bull 1988; 14: 116-22.

12 Logan WS. The evaluation of the impaired physician. New Dir Ment Health Serv 1989; 41: 33-53.

13 McAuliffe WE, Rohman $M$, Santangelo $S$, et al. Psychoactive drug use among practicing physicians and medical students. N Engl J Med 1986; 315: 805-10.

14 Angres $D H$, Busch $K A$. The chemically dependent physician: clinical and legal considerations. New Dir Ment Health Serv 1989; 41: 21-32.

15 Herrington RE, Benzer DG, Jacobson GR, Hawkins MK. Treating substance-use disorders among physicians. JAMA 1982; 247: 2253-7.

16 Menk EJ, Baumgarten RK, Kingsley $C P$, Culling $R D$, Middaugh $R$. Success of reentry into anesthesiology training programs by residents with a history of substance abuse. JAMA 1990; 263: 3060-2.

17 Talbott GD, Gallegos KV, Wilson PO, Porter TL. The medical association of Georgia's Impaired Physicians Program. JAMA 1987; 257: 2927-30.

18 Lecky JH, Aukburg SJ, Conahan TJ 3rd, et al. A departmental policy addressing chemical substance abuse. Anesthesiology 1986; 65: 414-7.

19 Lutsky I, Abram SE, Jacobson GR, Hopwood M, Kampine $J P$. Substance abuse by anesthesiology residents. Acad Med 1991; 66: 164-6.

20 Luetgert MJ, Armstrong $A H$. Methodological issues in drug usage surveys: anonymity, recency and frequency. Int J Addict 1973; 8: 683-9.

21 Ewing JA. Detecting alcoholism. The CAGE questionnaire. JAMA 1984; 252: 1905-7.

22 Snedecor GW, Cochran WG. Statistical Methods, 6th Ed, Ames, IA: Iowa State University Press 1967; 246-8.

$23 \mathrm{Kahn} \mathrm{HA}$. An introduction to Epidemiologic Methods. New York: Oxford University Press, 1983; 100-11.

24 Pokorny $A D$, Solomon J. A follow-up survey of drug abuse and alcoholism teaching in medical schools. Journal of Medical Education 1983; 58: 316-21.

25 Lewis $D C$, Niven RG, Czechowicz D. Trumble JG. A review of medical education in alcohol and other drug abuse. JAMA 1987; 257: 2945-8. 